\title{
Os dois "Prebischs" 1
}

\section{Pedro Cezar Dutra Fonseca ${ }^{2}$}

Biografia, sabe-se, é um gênero considerado difícil. Nem sempre o autor encontra a dosagem adequada entre o relevante e o detalhe pitoresco, ou entre o relato da vida pessoal do biografado e de sua trajetória profissional (essa mais ainda quando se trata, como no caso, de Raúl Prebisch), assim como entre os feitos do indivíduo e sua devida contextualização histórica. Não é o caso desta bem sucedida obra de Edgar J. Dosman, professor do Departamento de Ciência Política da Universidade de York, Canadá. Em suas mais de 600 páginas o leitor é convidado, em estilo ágil e vigoroso, a acompanhar a trajetória de Prebisch desde seu nascimento no interior argentino (Tucumán, 1901) até sua morte (Santiago do Chile, 1986).

Não se trata de uma exegese da vasta obra de Prebisch, a qual é arrolada ao final do livro, em louvável cooperação com os pesquisadores do pensamento econômico latinoamericano. Todavia, traz à liça o pano de fundo e as motivações que ajudam a entender melhor sua inquietação intelectual e, dessa forma, seus trabalhos, sempre enfocando dois planos que se entrelaçam: a conjuntura internacional e argentina, de um lado, e, de outro, as percepções, decisões e formas de pensar e de agir do biografado. Essa metodologia de exposição é um ponto forte do livro, do qual não pode deixar de mencionar a exaustiva pesquisa em fontes primárias e a farta documentação.

A complexa personalidade de Prebisch e sua atuação sempre decidida, com adversários de matizes tão diversos no espectro político - peronistas, comunistas, nazifascistas, rentistas da "oligarquia rural", isso só na Argentina -, além de embaixadores ingleses e norte-americanos, cada um vendo nele algo que incomodava, levaram o autor a sintetizar, em certo momento, na metáfora que talvez existissem "dois Prebischs" (p. 121): um, inspirador e ideólogo do latino-americanismo, da substituição de importações e do estruturalismo cepalino; e outro, mais conservador, aprendiz de Pareto, a confiar que cabia a uma elite burocrático-racional papel relevante na transformação das sociedades, e daí afirmar: "Sou um tecnocrata e acredito na tecnocracia. Os técnicos são politicamente neutros" (p. 121). As objeções a Prebisch em seu país enquanto era reconhecido e até ovacionado no exterior ajudam a evidenciar que a maior resistência a ele sempre foi política, a contrariar suas convicções paretianas. A existência de duas retóricas em

(1) Resenha de Dosman, Edgar. Raúl Prebisch (1901-1986); a construção da América Latina e do Terceiro Mundo. Rio de Janeiro: Contraponto/Centro Internacional Celso Furtado, 2011. 656p.

(2) Professor da Faculdade de Ciências Econômicas da Universidade Federal do Rio Grande do Sul (UFRGS), Porto Alegre, RS, Brasil. E-mail: pedro.fonseca@ufrgs.br. 
Prebisch já havia sido assinalada com propriedade por Bianchi (2002). Mesmo em um tema polêmico e divisor de águas - como capital estrangeiro -, ele assumia certa ambigüidade ao defender a existência de dois tipos: um do passado, vinculado ao modelo agroexportador e prejudicial, e outro, bem-vindo, disposto a colaborar com a industrialização latino-americana, aos moldes do que à época se chamou de "modelo dependente-associado" (Prebisch, 1963, p. 71).

Formado em contabilidade - fato que os críticos de seus trabalhos econômicos exploravam ao ironizá-lo tratando-o como "contador" - Prebisch desde a década de 1920 resolveu acompanhar séries estatísticas de preços dos principais itens da balança comercial argentina. Aí encontrou os primeiros indícios da tese que o consagraria mais tarde, principalmente com o "Manifesto" da Cepal de 1949, em Havana: a deterioração dos termos de troca. Celso Furtado teria lido uma versão preliminar do documento e, desapontado, considerou-o "acadêmico e defensivo": Prebisch alterou seu tom, e talvez deva a Furtado pelo menos parte da aclamação recebida pela maior parte da platéia, enquanto outro lado discordava do que ouvia (quem era esse argentino para afrontar o principal pilar do mainstream do comércio internacional, com a pretensão de revogar a lei das vantagens comparativas?).

Sua tese não era em si novidade: já aparece em List, no século XIX, e mais tarde em Mihail Manoilescu, Gustav Cassel e Hans Singer, sem contar a tradição marxista, em diferentes versões da "troca desigual" e das teorias de imperialismo. Mesmo no Brasil consta em discursos de políticos, militares e empresários já antes de 1930, como Vargas, Serzedelo Correa, Alcindo Guanabara e Jorge Street (Fonseca, 2000) . Todavia, o vigor do trabalho de Prebisch e sua repercussão obrigaram nomes como Haberler, Badwin, Kindleberger e Viner debruçarem-se sobre o tema numa tentativa de réplica. Até hoje talvez seja o único programa de pesquisa que partiu da "periferia" para o "centro", ao se manter o próprio linguajar do "Manifesto". Penso que três fatos se associam para explicar seu impacto, evento narrado por Dosman com paixão: um histórico, outro metodológico e um terceiro político.

Quanto às motivações históricas, não há como dissociá-las do fenômeno do desenvolvimentismo, que desde a década de 1930 ganhara impulso nos mais importantes países da América Latina. Internacionalmente o mundo do pós-Segunda Guerra trouxe consigo novas concepções que marcaram o "espírito da época", para usar a expressão de Hegel: a era do planejamento, dos governos intervencionistas, do keynesianismo e da social-democracia. Na América Latina, em particular, a emergência dos segmentos urbanos e da industrialização, a qual se afirmava como alternativa à agroexportação desde a década de 1930, fomentava reivindicações de ampliação de direitos sociais em vários países, num quadro internacional de Guerra Fria. Prebisch não hesitava em defender o desenvolvimento e a diminuição das desigualdades como as alternativas mais civilizadas 
ao comunismo, num discurso que empolgava muitos, mas assustava outros. Num mundo polarizado, tal ideologia soava como dubiedade e a polêmica tornava-se inevitável. Ao propor um conjunto de reformas, mas, ao mesmo tempo, defendê-lo circunscrito no horizonte ideológico "cristão-ocidental”, acabava não raramente por desagradar a gregos e troianos. Em segundo lugar, o trabalho de Prebisch alicerçava-se em séries históricas bem construídas; antes de ter uma teoria, ele pretendia convencer com uma constatação. Fundava sua análise, portanto, em um preceito metodológico caro ao positivismo difuso dominante na academia neoclássica: se a ciência deve se submeter ao "altar dos dados", ele recorria a material empírico para confrontar com a lógica abstrata dos modelos. Se o "fazer ciência" reconhece validade para hipóteses irrefutáveis e se o critério for esse (o empirismo) para validar teorias, a crença nas vantagens comparativas só poderia ser explicada pela irracionalidade da fé. Em terceiro lugar, e não menos importante, deve-se lembrar que a retórica de Prebisch mais chocava, ganhava efetividade e respeitabilidade porquanto partia de alguém já famoso e que nunca fora esquerdista ou avesso ao capital estrangeiro. Ademais, já era figura ilustre em um país que, embora agrícola, exibira a segunda renda per capita do mundo e com indicadores sociais invejáveis pela maior parte da Europa. Estivera à frente ou participara do primeiro escalão de equipes responsáveis por políticas marcadamente ortodoxas, como nos governos de Uriburu e de Ramon Castillo, na década de 1930 (na mesma época que o governo brasileiro optava por uma heterodoxia intervencionista). Acreditava que, diante da crise, a Argentina precisava de um regime de comércio internacional estável; a credibilidade da política austera, pensava, atrairia capitais ao país, numa crença vã numa época em que a própria Grã-Bretanha abandonava o padrãoouro. Seus amigos no Brasil eram Gudin e Octávio Gouvea de Bulhões, ambos fascinados pela pioneira decisão de Prebisch de convencer o governo argentino já em 1935, aos 34 anos, a criar um banco central com bastante autonomia - feito só possível no Brasil em 1964, e sem a autonomia sonhada.

Em Havana, em 1949, parecia um outro Prebisch a discursar, ao incitar os países latino-americanos a um programa econômico diverso do mainstream e avesso aos interesses norte-americanos, os quais se expressaram na posição contrária a criar uma comissão econômica voltada para a América Latina, ou seja, a Cepal, quando os mesmos Estados Unidos estimulavam a criação de comissões semelhantes nos outros continentes. Justo ele, que estampara em letras douradas, na entrada do Banco Central argentino, um lema para nenhum membro da já famosa Escola de Chicago por defeito: "A missão primeira e fundamental do Banco Central da Argentina é preservar o valor da moeda". Não por acaso uma das primeiras ações de Perón foi intervir no Banco Central. Dosman documenta que mais de uma vez Prebisch tentou explicar ao presidente a importância da autonomia, mas este se negou reiteradamente a recebê-lo. Para Perón, o banco deveria ser, a partir de então, da "nação argentina". Dosman assume a posição de Prebisch ao denunciar o "populismo peronista", numa técnica de narração que não esconde sua paixão 
pelo objeto de sua análise - procedimento corriqueiro em trabalhos biográficos, conquanto com o risco de perder em convencimento. Só não sai prejudicado porque Perón abusa do "irrealismo fantástico" ao denunciar Prebisch como representante do imperialismo inglês e norte-americano na Argentina, nega-se a participar de Bretton-Woods e demonstra clara simpatia pelo Eixo, sendo o último país do mundo a romper com o nazismo (declara guerra à Alemanha e ao Japão somente em março de 1945). Prebisch lamenta essas opções do governo de seu país e olha com certa inveja para o Brasil: na visão de um argentino envaidecido por sua nação, um país atrasado, mas que ora se industrializava, crescia a taxas sem paralelo e ultrapassava o PIB argentino, presidido por um Vargas também nacionalista mas pragmático, capaz de barganha e de visão de mais largo prazo, e que se aliara desde cedo aos vencedores da guerra.

Todavia, a seriedade do trabalho de Dosman não esconde elementos para o leitor, se quiser, ponderar com dois pesos. O Banco Central fora concebido por Prebisch como uma "empresa mista" e sua autonomia do governo assentava-se numa composição muito particular: "Apenas um dos doze diretores seria nomeado pelo governo, com os restantes sendo escolhidos a partir de uma base ampla (sic): um pelo Banco de La Nación, o Banco da Província de Buenos Aires e os outros bancos provinciais acionistas; três seriam selecionados pelos bancos comerciais argentinos e mais dois seriam escolhidos por uma assembléia dos bancos estrangeiros que atuavam no país" (p. 125). Fica para o leitor decidir: leia mais uma vez a composição da diretoria, confira qual o peso de cada segmento e avalie se Perón não devia ter lá suas razões, com os bancos internacionais com o dobro da representação do governo e o setor bancário com ampla maioria na direção de uma instituição justamente voltada a promover o marco regulatório e a fiscalização do setor. Será que, por isso, o Chase Manhattan Bank se referira a ele como "membro da família" (p. 269)? E será que a posição de Perón, rompantes à parte, pode ser interpretada rasamente como demagogia populista? A recorrência ao populismo por parte de Prebisch para rotular vários governos reformistas, como Perón e Allende, é assimilada por Dosman. Assim, o uso do termo, polissêmico e de conotação sempre depreciativa, cuja antítese semântica remete à seriedade e à responsabilidade, permite que se avalie quanto seu uso se presta para proliferar acriticamente.

Da mesma forma, há expressões e afirmações que surpreendem ou não ficam claras para o leitor. É o caso de considerar, acriticamente, a afirmação atribuída a Prebisch que o povo paraguaio é "pobre mas digno" (p. 232). E mais: que hoje a tese de Prebisch segundo a qual as economias periféricas devem transitar de uma produção de produtos primários a uma economia industrial mais diversificada "é óbvia" (o mainstream abandou a teoria das vantagens comparativas? $\mathrm{O}$ debate brasileiro sobre a reprimarização que $\mathrm{o}$ diga...) (p. 282); ou que a entrada do Brasil na II Guerra ao lado dos Estados Unidos teria sido a causa maior de seu crescimento, pois "lhe assegurou uma era de expansão sem precedentes" (p.179). Também para o leitor não fica claro o hiato entre a posição do 
governo brasileiro em 1951-52 de ser contrário à intenção de Truman de fechar a Cepal, atitude reconhecida por Dosman como fundamental para a manutenção da agência (p. 299), com a defesa do ponto de vista segundo o qual a Cepal era pouco conhecida no Brasil, "a começar pelo próprio presidente Vargas", que apenas assim se posicionara "com o intuito de confundir os americanos" (p. 321) - argumento, no mínimo, difícil de convencer.

Além dessas passagens já mencionadas, o Brasil aparece na obra através das menções a Celso Furtado, considerado da "divisão vermelha", grupo mais à esquerda da Cepal. Dessas pode-se depreender que a relação entre os dois foi próxima, mas nem sempre de plena harmonia. Prebisch mostrara simpatia pelo golpe militar que derrubou Perón, liderado por Eduardo Lonardi e, em 1956, a pedido de Aramburu, fez um plano para "salvação" da Argentina marcadamente ortodoxo, com cortes de pessoal e de orçamento, privatização de empresas estatais e liberalização do câmbio, dentre outras medidas: "Só a austeridade e o sacrifício podem salvar a Argentina" (p. 351). Furtado teria ficado "perplexo e desapontado" (p. 360) - tratava-se da mesma pessoa que conhecera no Chile à frente da Cepal? Mais séria parece ter sido a decisão de Prebisch de não publicar um estudo de Furtado sobre a economia mexicana no qual despendera dois anos de trabalho, por "não se ajustar completamente" à tese, então em elaboração por Prebisch, crítica à industrialização por substituição de importações na Argentina: o "fechamento" da economia trouxera problemas ao país, como o aumento das desigualdades; dever-se-ia estimular as exportações e não priorizar o mercado interno. Furtado mostrava, ao contrário, que o México era um caso semelhante ao do Brasil, bem sucedido. O problema não estava na substituição de importações, e cabia ao governo estabelecer políticas regulatórias mais eficazes para evitar uma tendência persistente de concentrar renda nas classes mais altas. $\mathrm{O}$ veto do dirigente maior a um trabalho já aprovado levou Furtado a pedir demissão da Cepal, instituição na qual chegara antes do próprio Prebisch.

O trabalho de Dosman, pela riqueza de informações, torna-se leitura obrigatória para todos os interessados em economia e em pensamento econômico e instituições da América Latina. Impressiona sua narrativa de como a força do peronismo na Argentina tornou Prebisch quase um exilado em seu próprio país. Em contraste, merecia reconhecimento internacional, com convites para ministrar cursos e palestras nas mais importantes universidades do mundo, como Princeton, Yale, Harvard, Columbia, Johns Hopkins e Boston, ao lado de nomes como Haberler, Samuelson, Triffin, Musgrave, Kindleberger, Hansen, Von Mises, Schumpeter, Viner, Baran e Jonh Williams. O único latino-americano a ser indicado (duas vezes) para o Prêmio Nobel de Economia, com aval de outros ganhadores anteriores como Tinbergen, Samuelson, Myrdal e Leontief, mas impedido de receber o título de Doutor Honoris Causa pela Universidade de Tucumán devido a uma série de protestos dos professores da instituição, fenômeno ao qual Dosman se refere como "prebischfobia". 
O livro, em parceria com a editora Contraponto, faz parte de um louvável esforço de publicação do Centro Internacional Celso Furtado, responsável nos últimos anos pela divulgação de excelentes trabalhos, inclusive inéditos e até então de difícil acesso, sobre a temática do desenvolvimento. Por falar em Furtado, o episódio de sua polêmica demissão permite desvelar traços como o autoritarismo e a arbitrariedade de Prebisch, se nos ativermos ao fato em si. Todavia, cum grano salis e em compensação, não podemos deixar de agradecer a ele por sua conseqüência: Furtado saiu do Chile e foi para Cambridge, onde encontrou ambiente fértil para realizar seu projeto de escrever Formação Econômica do Brasil - a obra-prima do estruturalismo brasileiro e o livro de economia do país com maior reconhecimento internacional, haja vista o número de traduções e reedições. Muchas gracias!

\section{Referências bibliográficas}

BIANCHI, Ana Maria. For different audiences, different arguments: economic rhetoric at the beginning of the Latin American School. Journal of the History Economic Thought, v. 24 , n. 3, p. 291-305, 2002.

FONSECA, Pedro Cezar Dutra. As origens e as vertentes formadoras do pensamento cepalino. Revista Brasileira de Economia, v. 54, n. 3, jul./set. 2000. 